\title{
The Optimization of Solar Water Heating System Using Hybrid Algorithm (PSO/HJ) for Different Locations of Turkey
}

\begin{tabular}{|l|l|}
\hline \multicolumn{1}{|c|}{ Kaan Yaman $^{1}$, Gökhan Arslan"1 } \\
\hline${ }^{1}$ Mersin University, Faculty of Engineering, Department of Mechanical Engineering, Çiftlikköy, 33343, Mersin, TURKEY \\
\hline \\
\hline Başvuru/Received: 08/10/2017 $\quad$ Kabul/Accepted: 01/12/2017 $\quad$ Son Versiyon/Final Version: 26/12/2017 \\
\hline
\end{tabular}

\begin{abstract}
In this study, optimum dimensions of Solar Domestic Hot Water System (SDHWS) were determined according to initial capital cost and energy consumption cost in different locations of Turkey. Typical Meteorological Year (TMY) data of 12 different locations which represent climatic characteristics of Turkey were used. Analysis was performed by using Particle Swarm Optimization /

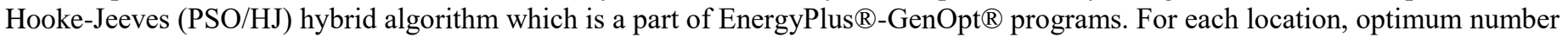
of solar collectors and hot water storage tank volume was determined. Initial investment and energy consumption costs decreased $6.1 \%$ for Gaziantep whereas solar fraction increased $42.8 \%$ for Ankara. In average, $4.5 \%$ decrease in initial investment and energy costs and $35.4 \%$ increase in solar fraction were obtained.
\end{abstract}

\section{Key Words}

"Solar energy, domestic hot water, optimization, hybrid algorithm." 


\section{INTRODUCTION}

Global warming, climate change, and the greenhouse effect, as well as the rise in energy prices, have become popular nowadays. According to the International Energy Agency 2014 data, the capacity of solar water heating systems (SDHWS) worldwide is 410.2 GW, whereas in Turkey, about $9.4 \mathrm{GW}$ of thermal energy was produced by SDHWS in 2015 according to the General Directorate of Energy Affairs (Mauthner et al., 2014; MENR, 2017). Increasing these values with future work is key to reduce dependence on fossil fuels and related emissions.

In the literature, various SDHWS design and optimization methods have been proposed and discussed. Many researchers were conducted design and optimization of SDHWS for solar fraction (Skerlić et al., 2013; Bernardo, 2013), life cycle cost (Atia et al., 2012; Ko, 2015), life cycle savings (Araya et al., 2017), and payback period (Kim et al., 2012). Some important related works are as follows: Kalogirou (2004) proposed an approach that can be used with artificial neural networks and genetic algorithm (GA) to design and optimize various SDHWS. The optimal collector area and storage tank volume were determined for life cycle savings (Kalogirou, 2004). Hobbi and Siddiqui (2009) obtained optimal solutions by parametric approach for many decision variables such as collector area, fluid type and mass flow rate, storage tank volume, heat exchanger effectiveness, collector's aspect ratio, diameter and length of connection pipe. Recently, Araya et al. (2017) implemented an SDHWS optimization method by using GA that provides life cycle savings to 182 locations in Chile and 6 consumption profiles. Karaçavuş (2017) investigated the optimal storage tank volume, collector tilt and area for Turkey's limited number of climatic regions (Ankara, Edirne, Hakkari, İzmir, and Trabzon).

SDHWS requires careful examination of its thermal and economic performance. However, it is propounded that climate has an important effect on system performance. Thus, this paper focused to increase the number of related studies on SDHWS design and optimization. In this regard, a methodology was presented to optimize the life cycle cost of an SDHWS. In order to determine the effect of different climatic conditions, this methodology was implemented in different climatic regions of Turkey.

The remainder of the paper is organized as follows. In Sect. 2, the background of the simulation and optimization method is explained. In Sect. 3, the validation of the model is demonstrated. In Sect. 4, model results are presented and discussed. Finally, the paper concludes with inferences in Sect. 5.

\section{MATHEMATICAL MODEL}

SDHWS performance is affected by many parameters: solar radiation, ambient temperature, collector and tank characteristics and constructions etc. For the simulation-optimization, a mathematical model of an SDHWS was established.

\subsection{Reference climatic conditions}

To evaluate the impact of the climate on the performance of the SDHWS, 12 regions representing the general climate of Turkey were selected, including Ankara, Bursa, Çanakkale, Erzincan, Gaziantep, Istanbul, Izmir, Kayseri, Konya, Malatya, Mersin, and Muğla. The typical meteorological year (TMY) weather files (resolution $1 \mathrm{~h}$ ) were used for these regions. In Table 1, coordinates of the locations are summarized.

Table 1. Coordinates of the locations.

\begin{tabular}{|l|l|l|c|}
\hline Locations & Latitude $\left({ }^{\circ} \mathbf{N}\right)$ & Longitude $\left({ }^{\circ} \mathrm{E}\right)$ & Altitude $(\mathbf{m})$ \\
\hline Ankara & 40.0 & 32.9 & 902 \\
\hline Bursa & 40.2 & 29.1 & 100 \\
\hline Çanakkale & 40.1 & 26.4 & 3 \\
\hline Erzincan & 39.7 & 39.5 & 1215 \\
\hline Gaziantep & 37.1 & 37.4 & 855 \\
\hline Istanbul & 41.0 & 29.1 & 33 \\
\hline Izmir & 38.4 & 27.2 & 25 \\
\hline Kayseri & 38.8 & 35.4 & 1054 \\
\hline Konya & 38.0 & 32.6 & 1028 \\
\hline Malatya & 38.4 & 38.1 & 849 \\
\hline Mersin & 36.4 & 33.9 & 15 \\
\hline Muğla & 37.2 & 28.4 & 646 \\
\hline
\end{tabular}




\subsection{SDHWS description}

Optimization problem which considered to provide domestic hot water (DHW) demand of single family is an actual SDHWS. The schematic view of the basic components of the system is shown in Fig. 1.

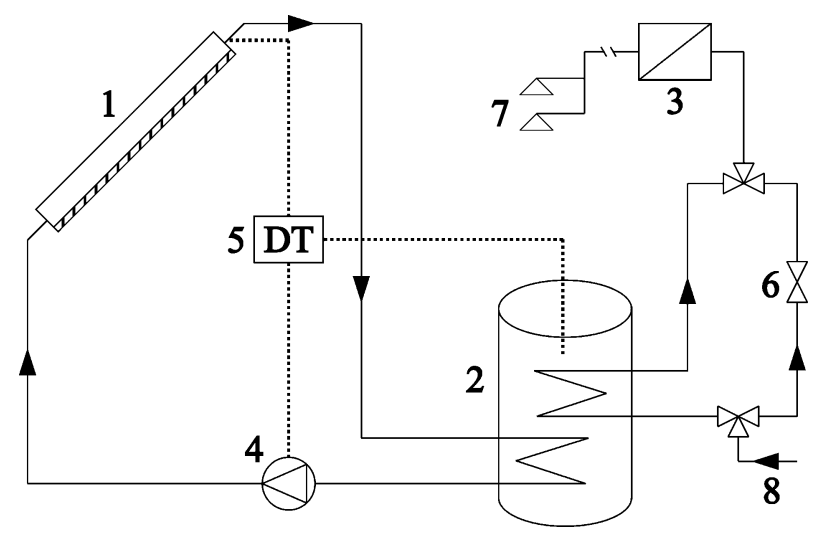

Fig. 1. Actual SDHWS: (1) flat-plate collector, (2) storage tank, (3) instantaneous water heater, (4) circulation pump, (5) differential thermostat, (6) tempering valve, (7) load, and (8) mains water.

The system is typically closed loop and consists of a flat-plate solar collector, a hot water storage tank and a circulation pump. The system meets the energy demand with natural gas in case solar energy is inadequate. In addition, the system is equipped with a differential thermostat (DT) that operates according to the solar collector output and storage tank temperature difference. Thus, if the temperature difference is higher than $5^{\circ} \mathrm{C}$, then the circulating pump starts and stops when that difference is below $2{ }^{\circ} \mathrm{C}$. Energy analysis for each component of the system was performed with EnergyPlus (v8.4) software. The thermal efficiency of the collector is described using the Hottel-Whillier-Bliss equation (ASHRAE, 2001).

$\eta=a_{0} K_{\theta}-a_{1} \frac{\left(T_{i n, S C}-T_{a m b}\right)}{I_{\text {solar }}}+a_{2} \frac{\left(T_{i n, S C}-T_{a m b}\right)^{2}}{I_{\text {solar }}}$

and

$K_{\theta}=1-b_{0}\left(\frac{1}{\cos (\theta)}\right)-b_{1}\left(\frac{1}{\cos (\theta)}\right)^{2}$

where the optical efficiency, first- and second- order heat loss coefficients were determined according to the Solar Rating \& Certification Corporation (SRCC, 2017). The test results of SRCC (2017) are ao=0.6, a1=-3.87, and a2=0.002. Tin is fluid temperature at the collector inlet; Tamb is the ambient air temperature; Isolar is global solar radiation on the solar collector surface. Finally, $\mathrm{K} \theta$ is the incidence angle modifier and $\theta$ is incidence angle and bo, b1 are -0.194 and -0.019 , respectively.

The solar collector -net surface area $0.93 \mathrm{~m} 2$ - was designed and manufactured by ACR solar (2017). The collector was oriented to the south $\left(0^{\circ}\right)$ and the tilt angle was set to be equal to $38.8^{\circ}$, that is the mean of the latitudes of all the regions. Moreover, the collectors were installed in the system as 4 units.

Temperature difference in the storage tank affects SDHWS thermal performance. The cylindrical storage tank was divided into 5 nodes with equal distance with each other and the height to diameter ratio was selected as 3 . The volume of the storage tank was $200 \mathrm{~L}$ and the overall heat transfer coefficient was assumed as $0.8 \mathrm{~W} / \mathrm{m} 2 \mathrm{~K}$. The energy balance at each node as defined by the following expression (Araya et al., 2017; Duffie \& Beckman, 2006):

$M_{s, n} c_{p} \frac{d T_{s, n}}{d t}=U_{s} A_{s, n}\left(T_{a m b}-T_{s, n}\right)+\frac{k A_{s, n+1}\left(T_{s, n+1}-T_{s, n}\right)}{\Delta x}+\frac{k A_{s, n-1}\left(T_{s, n-1}-T_{s, n}\right)}{\Delta x}+\dot{Q}_{n+1}+\dot{Q}_{n-1}+\dot{Q}_{1}+\dot{Q}_{5}$ 
$\dot{Q}_{n+1}=\left(\dot{m}_{L}-\dot{m}_{c}\right) c_{p}\left(T_{s, n+1}-T_{s, n}\right)$, if $\dot{m}_{c}<\dot{m}_{L}$

$\dot{Q}_{n-1}=\left(\dot{m}_{c}-\dot{m}_{L}\right) c_{p}\left(T_{s, n-1}-T_{s, n}\right)$, if $\dot{m}_{c}>\dot{m}_{L}$

$\dot{Q}_{1}=\dot{m}_{L} c_{p} T_{\text {mains }}-\dot{m}_{c} c_{p} T_{s, 1}$, if $n=1$

$\dot{Q}_{5}=\dot{m}_{c} c_{p} T_{\text {out }}-\dot{m}_{L} c_{p} T_{s, 5}$, if $n=5$

where the storage tank inlet of water mains is located on node 1 and the outlet of storage tank is located on node 5 . Ms is mass of the storage tank; $\mathrm{m}$ is the flow rate and represent subscript $\mathrm{c}$ for collector, $\mathrm{L}$ for load, and $\mathrm{s}$ storage tank; $\mathrm{T}$ is the temperature, represent subscript amb for ambient, mains for mains water; U and A are the storage tank area and overall heat loss coefficient, respectively.

Auxiliary energy $\left(\dot{Q}_{a u x}\right)$ is determined by using Eq. (8).

$\dot{Q}_{\text {aux }}=\eta_{\text {aux }} \dot{m}_{L} c_{p}\left(T_{L}-T_{s, n=5}\right)$

where $\eta$ aux is the heat exchanger efficiency. Finally, the system load $\left(\dot{Q}_{L}\right)$ is determined as:

$\dot{Q}_{L}=\dot{Q}_{a u x}+\dot{Q}_{S C}+\dot{Q}_{\text {Loss }}$

The instantaneous peak value of hot water usage is $0.08 \mathrm{~L} / \mathrm{s}$ and the daily total demand from the system is $300 \mathrm{~L}$ at $55{ }^{\circ} \mathrm{C}$. The DHW profile is defined according to the ASHRAE 90.2 (2001) standard.

\subsection{Optimization framework}

In this study, particle swarm optimization (PSO) algorithm proposed by Kennedy and Eberhart $(1995,1997)$ then developed by Clerc and Kennedy (2002) with a constriction coefficient, and Hooke-Jeeves (HJ) (1961) hybrid optimization algorithm (PSO/HJ) was used. Wetter and Wright (2004) shown that using hybrid algorithms improves optimization performance. Thus, researchers have tried to make up algorithm's shortage by using another one. However, Nguyen et al. (2014) reported that hybrid algorithms were used less frequently than the other methods, based on 200 studies in the literature. In PSO algorithm is a population-based optimization method inspired by the social behavior of birds and the birds-like species. The particles -solution- in the population randomly generated by the PSO algorithm are assigned to their random initial positions $(x)$ and velocities $(v)$ by using the Eqs. (10) and (11), respectively.

$v_{i}^{k+1}=X\left[v_{1}^{k}+c_{1} \varphi_{1}^{k}\left(p_{l, i}^{k}-x_{i}^{k}\right)+c_{2} \varphi_{2}^{k}\left(p_{g, i}^{k}-x_{i}^{k}\right)\right]$

$x_{i}^{k+1}=x_{i}^{k}+x_{i}^{k+1}$

where $i$ is the particle number; $k$ is the iterations number; $\varphi_{1}$ and $\varphi_{2}$, are the randomly generated numbers between 0 and 1 . Acceleration coefficients are selected as $c_{1}=c_{2}=2.05$ (Clerc \& Kennedy, 2002). The PSO performance is improved by controlling the particle velocity with the constriction factor $X$. The constriction factor is expressed as (Clerc, 1999):

$X=\frac{2}{\left|2-\omega-\sqrt{\omega^{2}-4 \omega}\right|}$

where $\omega=c_{1}+c_{2}=4.1$. In the PSO algorithm, the number of particles and generations are limited to 15 and 20, respectively. The particles change their velocity and position relative to the best solution in the population. In this way, generations are updated to obtain the most appropriate values.

The PSO algorithm's solution is chosen as the starting point for the Hooke-Jeeves (1961) algorithm. HJ algorithm is searching for the most appropriate solution according to neighborhood relation at each iteration. The successful values obtained by HJ are 
assigned as the optimal solutions. The optimization problem of the SDHWS was utilized GenOpt® (v3.1). The GenOpt was chosen because it can combine with EnergyPlus. The PSO/HJ algorithm is embodied in the GenOpt. More detailed information was given by Wetter (2016).

\subsubsection{Decision Variables}

Kalogirou (2004) and Abdel-Malek (1985) emphasized that the most important parameters in SDHWS performance are collector number and storage tank volume. For this reason, those parameters were taken as independent parameters in the present study. Thus, decision variables vector is as follows.

$$
\vec{x}=[N, V]^{T}
$$

where $\vec{x}$ is the decision variables vector, $N$ is number of the solar collector, and $V$ is volume of the storage tank.

\subsubsection{Objective Function}

The proposed methodology minimizes the overall cost of the SDHWS throughout its life cycle of investment and energy consumption costs. LCC composes of three basic elements and can be formulated as follows:

$$
L C C=C_{i n v}+\left(C_{O \& M}+C_{E}\right) P W
$$

where

$$
\begin{aligned}
& C_{\text {inv }}=C_{c} N+C_{s} V+C_{\text {pump }} \\
& C_{O \& M}=\frac{C_{\text {inv }}}{t} 0.10 \\
& C_{E}=\frac{Q_{L} C_{\text {gas }}}{\eta_{\text {aux }}}+\frac{Q_{\text {pump }} C_{\text {elek }}}{\eta_{\text {pump }}}
\end{aligned}
$$

where $C_{i n v}, C_{O \& M}$, and $C_{E}$ represent the investment, maintenance \& operation, energy costs, respectively. $C_{c}, C_{s}$, and $C_{p u m p}$ are the collector, storage tank, and pump costs, respectively, and $t$ is the life-time. In Table 2, the SDHWS cost parameters are given. The present worth factor $(P W)$ is determined by using Eqs. (18); (19).

$W=\frac{1-\left(1+i^{*}\right)^{-t}}{i^{*}}$

$i^{*}=\frac{i-e}{1+e}$

where $P W$ is a function of interest rate $(i=\% 10)$ and inflation rate $(e=\% 9)$. Finally, the system life-time was assumed as 25 years.

Table 2. SDHWS cost parameters.

\begin{tabular}{llll}
\hline Components & Value & Unit & Ref. \\
\hline Solar collector & 309 & $\mathrm{TL} / \mathrm{m}^{2}$ & MEU (2017) \\
Storage tank & $3.1 V+666.9$ & $\mathrm{TL} / \mathrm{m}^{3}$ & MEU (2017) \\
Circulation pump & 884 & $\mathrm{TL}$ & MEU (2017) \\
Natural gas & 0.945 & $\mathrm{TL} / \mathrm{m}^{3}$ & EMRA (2017) \\
Electricity & 0.41 & $\mathrm{TL} / \mathrm{kWh}$ & EMRA (2017) \\
\hline
\end{tabular}

\subsubsection{Constrains}

One of the important effects in determining the optimal solutions of the SDHWS is the constraints that are constituted by the decision maker's wishes. Thus, a certain economic and thermal performance can be the optimal solution for the decision maker's 
needs. In this paper, constraints for decision variables were determined by the authors' experience and by the expertise of previous researchers and formulated as:

$\vec{x}=\left\{(N, V) \in \mathrm{Z}^{n} \times \mathrm{R}^{n} \mid a^{i} \leq x^{i} \leq u^{i} ; i \in(1, \ldots, n)\right\}$

where $a^{i}$ and $u^{i}$ show the lower and upper limit, respectively. The optimization problem tackled the discrete variables for $N \in$ $\{1,2, \ldots, 12\}$ and continuous variables for $V \in\{5, \ldots, 1000\}$. However, the solar fraction (SF) is constrained by using Eq. (21) to ensure system thermal performance.

$S F=\left(Q_{L}-Q_{a u x}\right) / Q_{L} \geq 0.4$

\section{Model validation}

The SDHWS mathematical model was compared with the experimental results that obtained by Ayompe and Duffy (2013) in Dublin, Ireland. A computer code was wrote to provide experimental conditions and to test the mathematical model. Thus, the same conditions were prepared for the system. Simulated results was evaluated with statistical criterion proposed by ASHRAE Guideline 14 (2002). Simulated results were evaluated according to normalized mean bias error N(MBE) and coefficient of variation of the root mean square error CV(RMSE). These parameters were calculated by using Eqs. (22); (23), respectively.

$$
\begin{aligned}
& N(M B E)=\frac{\sum_{i=1}^{n}\left(y_{\text {Exp }, i}-y_{\text {Simul }, i}\right)}{n-1} \frac{100}{\bar{y}_{\text {Exp }}} \\
& C V(R M S E)=\left[\frac{\sum_{i=1}^{n}\left(y_{E x p, i}-y_{\text {Simul }, i}\right)^{2}}{n-1}\right]^{1 / 2} \frac{100}{\bar{y}_{\text {Exp }}}
\end{aligned}
$$

where, $y_{\text {Exp }}$ and $y_{\text {Simul }}$ represent according to experimental and simulated results, respectively. $n$ is the number of simulated value. According to ASHRAE Guideline 14 (2002), acceptable tolerances for N(MBE) and CV(RMSE) are within $\pm 5 \%$ and $15 \%$, respectively.

Fig. 2 is illustrated the experimental and simulation results for auxiliary energy, and these results are in a good agreement. N(MBE) and CV(RMSE) are $-4.8 \%$ and $6.8 \%$, respectively. These values are within the tolerance that defined by ASHRAE Guideline 14 (2002).

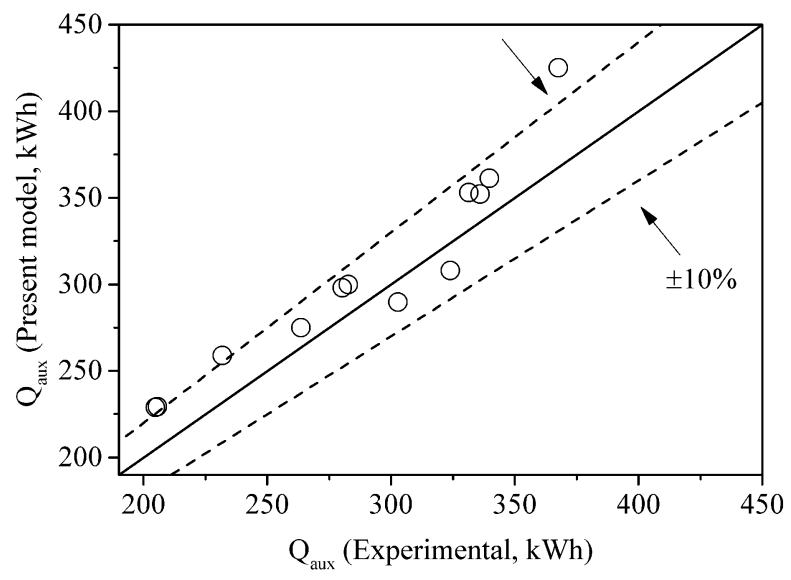

Fig. 2. Comparison of simulation and Ayompe and Duffy's (2013) experimental results.

\section{RESULTS AND DISCUSSIONS}

In this study, an SDHWS optimization was carried out under different climatic conditions. In Figs. 3 and 4, the optimization processes for only Erzincan and Mersin among 12 regions are shown in each iteration. The results of optimization for Erzincan and Mersin were presented in detail because they represent extreme weather conditions of Turkey. The PSO/HJ algorithm for Erzincan and Mersin reached the minimum value of LCC in $360^{\text {th }}$ and $356^{\text {th }}$ iterations, respectively. Whereas the optimal SDHWS for Erzincan is composed of $\vec{x}=\{7$ unit, $235.8 \mathrm{~L}\}$, it is $\vec{x}=\{7$ unit, $315.9 \mathrm{~L}\}$ for Mersin. However, the life cycle cost decreased by $3.3 \%$ for Erzincan and $5.9 \%$ for Mersin, while the annual solar fraction increased by $31.4 \%$ and $32.1 \%$, respectively. 


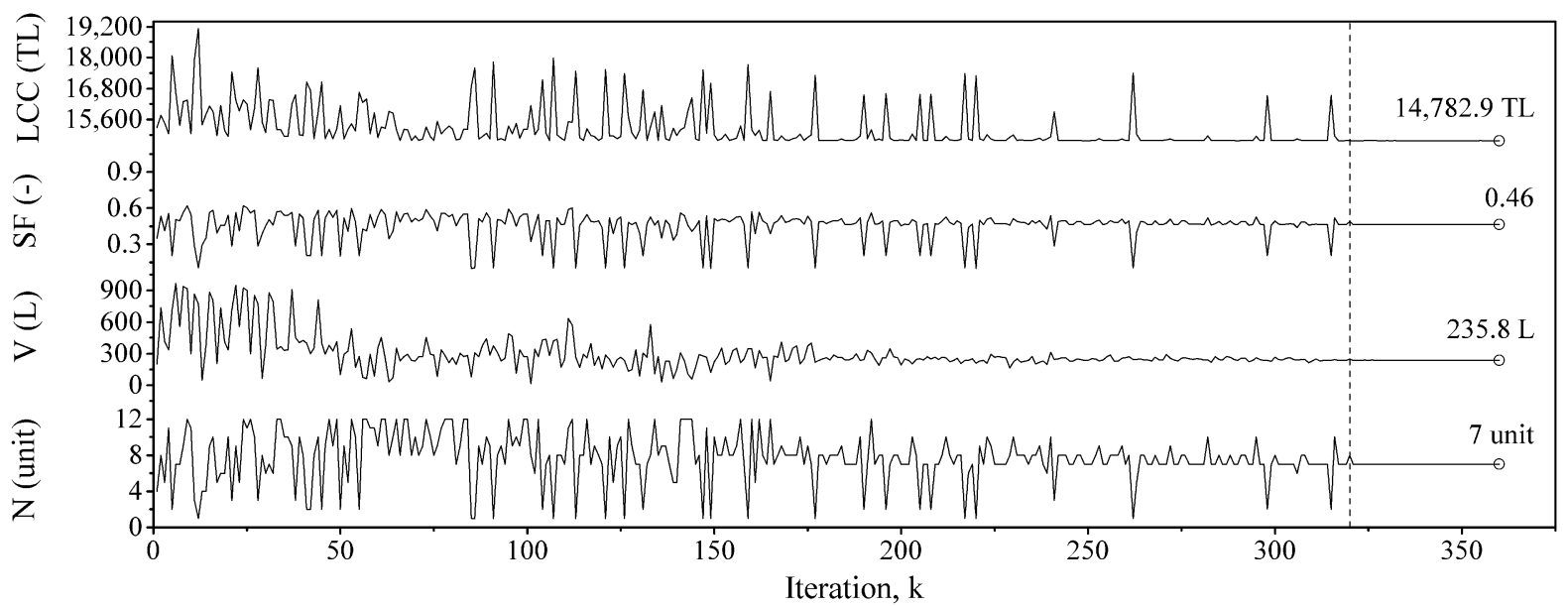

Fig. 3. Optimization of SDHWS in Erzincan; Circle-marking: Optimal solution and Dashed-line: PSO ending-HJ beginning.

The optimal results for each climate region are shown in Fig. 5 in terms of SF and LCC. In warm climates, it is expected that the LCC is lowest and the SF is highest, whereas it is opposite in cold regions. Thus, SF is high in Mersin and İzmir while LCC is high in Ankara and Erzincan. However, in mild climates, the increase of SF has a relatively positive effect on LCC in optimal solutions. Optimization results shown that the performance of an SDHWS can be improved by composing a design according to the climatic conditions.

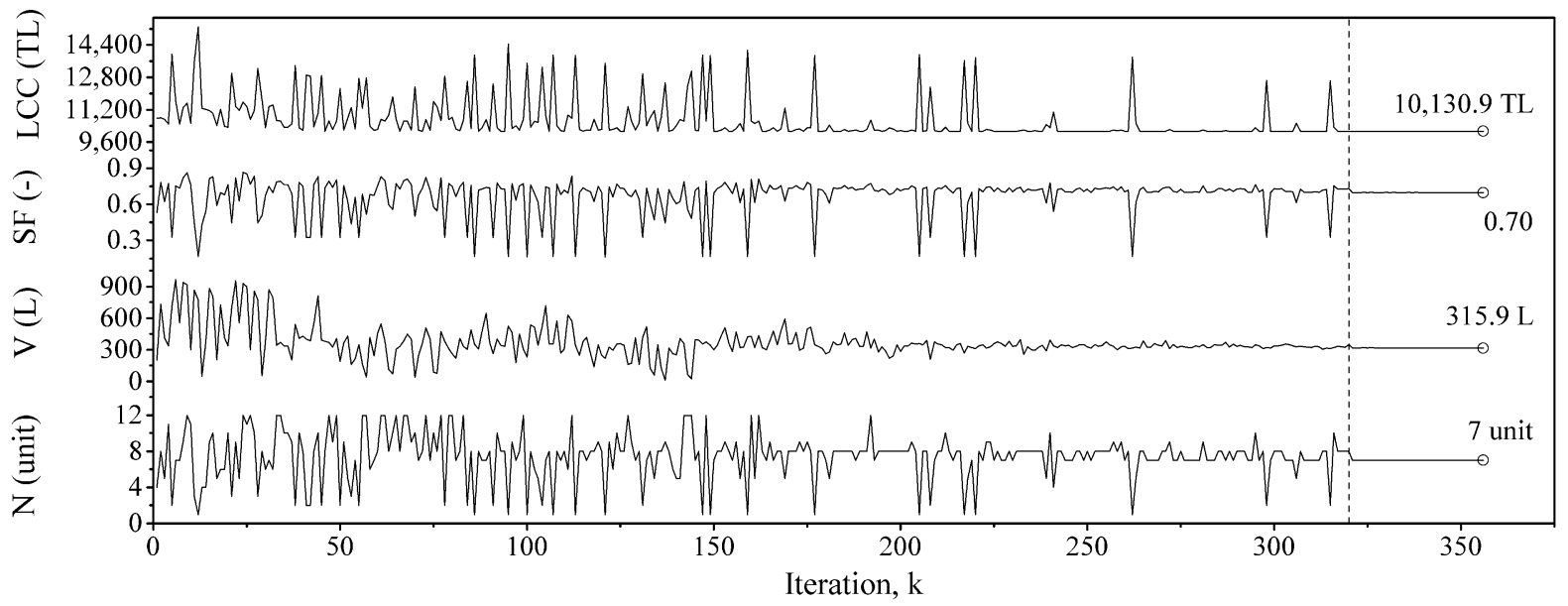

Fig. 4. Optimization of SDHWS in Mersin; Circle-marking: Optimal solution and Dashed-line: PSO ending-HJ beginning.

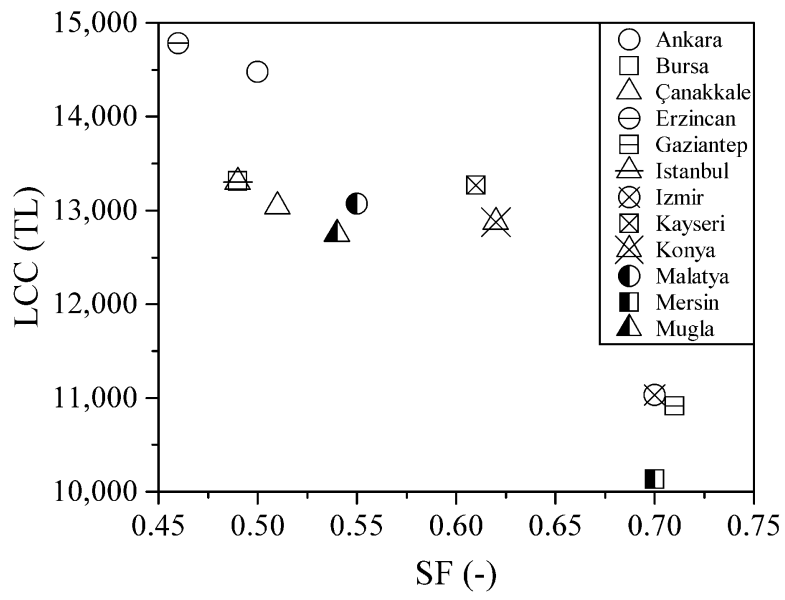


Fig. 5. Optimization results in each climate region for SF vs. LCC.

In Fig. 6, the optimization results are shown depending on the number of the collectors and storage tank volume. Variation of the number of collectors is only 1 unit, equal to $0.63 \mathrm{~m}^{2}$ net surface area, for all climate regions. Accordingly, the storage tank volume appeared to be an important parameter in optimal system design, when considering the effect of different climatic regions. Thus, the variation of the storage tank volume was between 231.8 and $345.8 \mathrm{~L}$. In warm climate regions, tank volume can be larger, whereas the opposite is recommended in cold climate regions. The large size of SDHWS technical capacities in warm climatic regions reduce the total cost. This phenomenon is the opposite in cold climates. In addition, the initial investment cost may be overlooked, when the energy cost is high.

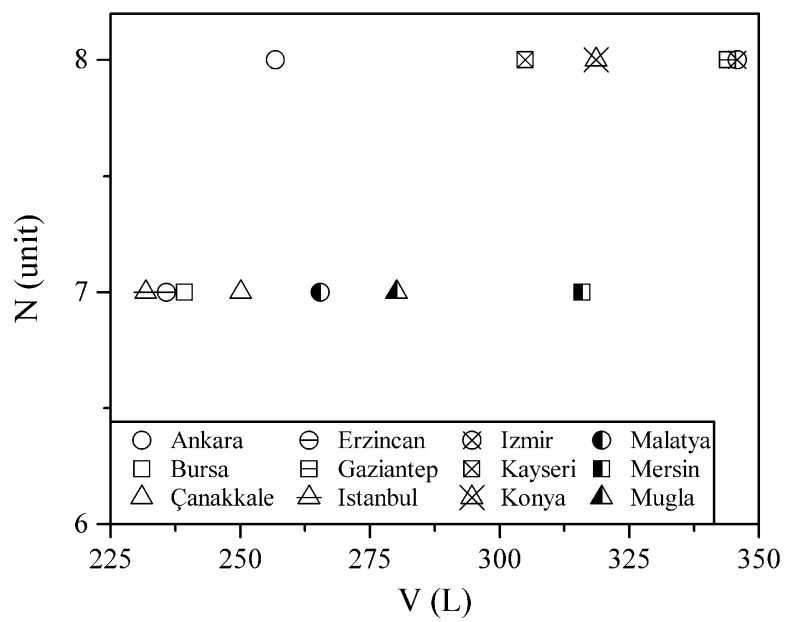

Fig. 6. Optimization results in each climate region for V vs. N.

Fig. 7 shows thermal and economic performance potential of SDHWS according to SF and LCC, respectively. The SDHWS performance potential is defined according to the percentage difference between the initial and optimal values. According to obtained optimal results, SF increased, while LCC decreased in all climate regions. Whereas the highest increase for SF was in Ankara (42.9\%), the highest decrease for LCC was in Gaziantep (6.1\%). According to all climatic regions, SF increased mean $35.4 \%$, while LCC decreased mean 4.5\%. This is possible according to Bornatico et al. (2012). Bornatico et al. (2012) indicated that investment and energy costs could be reduced as well as solar fraction could be increased.

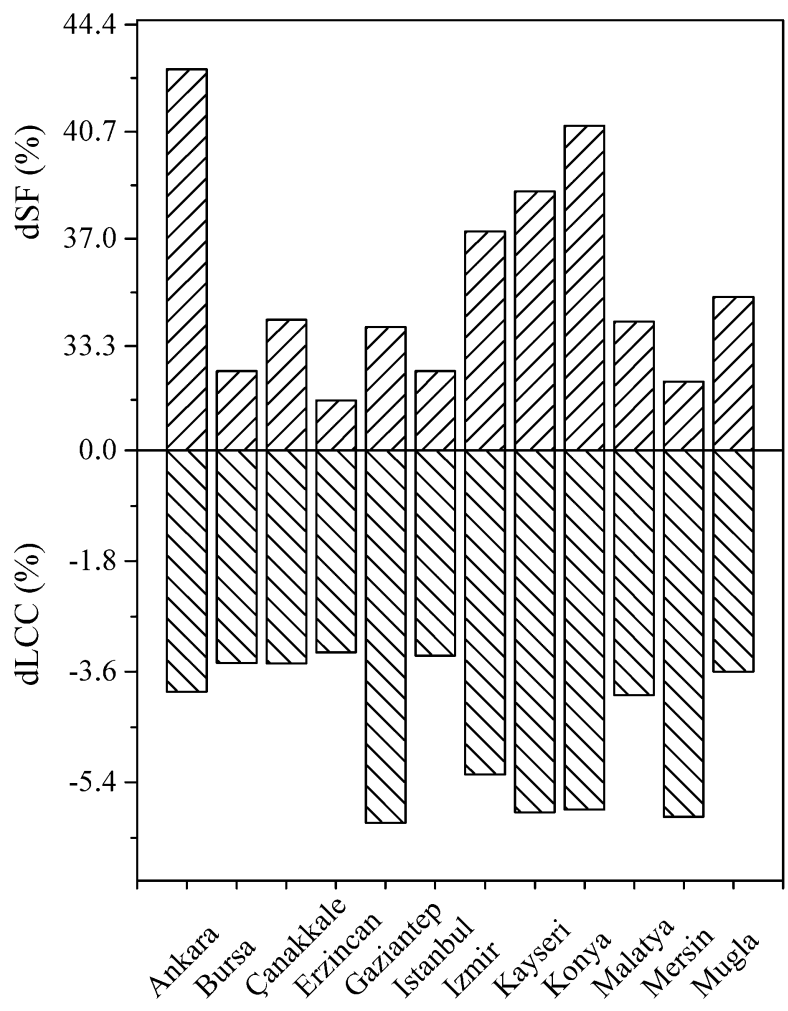


Fig. 7. Thermal and economic potentials in each climate region.

\section{CONCLUSIONS}

In this paper, a simulation-optimization method is presented to optimize the life cycle cost of an SDHWS. In order to determine the effect of different climatic conditions, this method was implemented in different climatic regions of Turkey. For all climate regions, the variation of the number of collectors is only 1 unit, equal to $0.63 \mathrm{~m}^{2}$ net surface area, whereas the variation of the storage tank volume is between 231.8 and $345.8 \mathrm{~L}$. The large size of SDHWS technical capacities in warm climatic regions reduce the total cost. This phenomenon is the opposite in cold climates. However, SF increased mean 35.4\%, and LCC decreased mean $4.5 \%$, according to all climatic regions. As a result, a proper design and optimization of SDHWS should be composed according to climate. In this way, SDHWS becomes more sustainable.

\section{References}

Abdel-Malek L. (1985). Optimum design of solar water heating systems. Comput Opt Res, 12(2), 219-225. doi: 10.1016/0305$\underline{0548(85) 90046-2}$

ACR solar. (2017). Retrieved from http://www.acrsolar.com/

Araya R., Bustos F., Contreras J., \& Fuentes A. (2017). Life-cycle savings for a flat-plate solar water collector plant in Chile. Renew Energy, 112, 365-377. doi: 10.1016/j.renene.2017.05.036

ASHRAE (2001). Handbook of Fundamentals. American Society of Heating, American Society of Heating, Ventilating, and Air Conditioning Engineers, Atlanta, GA.

ASHRAE 90.2. (2001). Energy efficient design of low-rise residential buildings, American Society of Heating, Ventilating, and Air Conditioning Engineers, Atlanta, GA.

ASHRAE Guideline 14. (2002). Measurement of Energy and Demand Savings, American Society of Heating, Ventilating, and Air Conditioning Engineers, Atlanta, GA.

Atia D. M., Fahmy F. H., Ahmed N. M., \& Dorrah H. T. (2012). Optimal sizing of a solar water heating system based on a genetic algorithm for an aquaculture system. Math Comput Model, 55(3-4), 1436-1449. doi: 10.1016/j.mcm.2011.10.022

Ayompe L. M. \& Duffy A. (2013). Analysis of the thermal performance of a solar water heating system with flat plate collectors in a temperate climate. Appl Therm Eng, 58(1-2), 447-454. doi: 10.1016/j.applthermaleng.2013.04.062

Bernardo L. R. (2013). Retrofitting conventional electric domestic hot water heaters to solar water heating systems in single-family houses-model validation and optimization. Energies, 6(2), 953-972. doi: 10.3390/en6020953

Bornatico R., Pfeiffer M., Witzig A., \& Guzzella L. (2012). Optimal sizing of a solar thermal building installation using particle swarm optimization. Energy, 41(1), 31-37. doi: 10.1016/j.energy.2011.05.026

Clerc M. \& Kennedy J. (2002). The particle swarm - explosion, stability, and convergence in a multidimensional complex space. IEEE Trans Evol Comput, 6, 58-73. doi: 10.1109/4235.985692

Clerc M. (1999). The swarm and the queen: towards a deterministic and adaptive particle swarm optimization. ICEC, Washington, DC, 1951-1957.

Duffie J. A. \& Beckman W. A. (2006). Solar Engineering of Thermal Processes, Hoboken, New Jersey: John Wiley \& Sons Inc.

EMRA. (2017). Republic of TURKEY Energy Market Regulatory Authority. Retrieved from http://www.emra...

org.tr/en/home.

Hobbi A. \& Siddiqui K. (2009). Optimal design of a forced circulation solar water heating system for a residential unit in cold climate using TRNSYS. Sol Energy, 83(5), 700-714. doi: 10.1016/j.solener.2008.10.018

Hooke R. \& Jeeves T.A. (1961). Direct search solution of numerical and statistical problems. J Ass Comput Mach, 8(2), 212-229. doi: $10.1145 / 321062.321069$

Kalogirou S. A. (2004). Optimization of solar systems using artificial neural-networks and genetic algorithms. Appl Energy, 77(4), 383-405. doi: 10.1016/S0306-2619(03)00153-3 
Karaçavus B. (2017). Optimization of solar domestic hot water system for certain climate zones of Turkey. J Fac Eng Archit Gazi Univ, 32(3), 843-853. doi: 10.17341/gazimmfd.337633

Kennedy J. \& Eberhart R. C. (1995). Particle swarm optimization. In IEEE International Conference on Neural Networks, Perth, Australia, 1942-1948.

Kennedy J. \& Eberhart R. C. (1997). A discrete binary version of the particle swarm algorithm. In Proc. of Systems, Man, and Cybernetics. 4104-4108.

Kim Y., Thu K., Kaur H., Singh C., \& Choon K. (2012). Thermal analysis and performance optimization of a solar hot water plant with economic evaluation. Sol Energy, 86(5), 1378-1395. doi: 10.1016/j.solener.2012.01.030

Ko M. J. (2015). Analysis and Optimization Design of a Solar Water Heating System Based on Life Cycle Cost Using a Genetic Algorithm. Energies, 8(10), 11380-11403. doi:10.3390/en81011380

Mauthner F., Weiss W., \& Spörk-Dür M. (2014). Solar heat worldwide-markets and contribution to the energy supply 2014. Technical report, International Energy Agency, Solar heating and cooling.

MENR. (2017). Solar. Retrieved from http://www.enerji.gov.tr/tr-TR/Sayfalar/Gunes.

MEU. (2017). The Ministry of Environment and Urbanization, Retrieved from http://www.csb.gov.tr/gm/donerser... maye/index.php?Sayfa=haberdetay\&Id=21332.

Nguyen A.-T., Reiter S., \& Rigo P. (2014). A review on simulation-based optimization methods applied to building performance analysis. Appl Energy, 113, 1043-1058. doi: 10.1016/j.apenergy.2013.08.061

Skerlić J., Radulović J., Nikolić D., \& Bojić M. (2013). Maximizing performances of variable tilt flat-plate solar collectors for Belgrade (Serbia). J Renew Sustain Energy, 5(4), 041820. doi: 10.1063/1.4819254

SRCC. (2017). The Solar Rating and Certification Corporation. Retrieved from http://www.solar-rating.org/.

Wetter M. \& Wright J. (2004). A comparison of deterministic and probabilistic optimization algorithms for nonsmooth simulationbased optimization. Build Environ, 39(8), 989-999. doi: 10.1016/j.buildenv.2004.01.022

Wetter M. (2016). GenOpt-generic optimization program user manual, version 3.1.1. Berkeley, CA, Lawrence Berkeley National Laboratory Report. 